\title{
Impaired Cerebrovascular Reactivity Predicts Recurrent Symptoms in Patients with Carotid Artery Occlusion: A Hypercapnia BOLD fMRI Study
}

\author{
S.D. Goode, N. Altaf, S. Munshi, S.T.R. MacSweeney, and D.P. Auer
}

\begin{abstract}
BACKGROUND AND PURPOSE: A key factor in predicting recurrent ischemic episodes in patients with carotid artery occlusion is the presence of hemodynamic impairment. There is, however, no consensus on how to best assess this risk in terms of imaging modalities or thresholds used. Here we investigated whether a predefined threshold of hemispheric asymmetry in hypercapnia fMRI predicts recurrent symptoms in patients with carotid artery occlusion.
\end{abstract}

MATERIALS AND METHODS: We studied 23 patients ( 2 women) with a mean age of $67.5 \pm 9$ years. Patients were assessed for recurrent ischemic events until lost to follow-up, study end, death, or recurrent ischemic event. Hypercapnia fMRI was used to assess the cerebrovascular reserve and quantify the percentage signal change in GM in the MCA territory and the hemispheric asymmetry index. KaplanMeier survival analysis and log-rank tests were performed to assess differences between patients with normal or abnormal hemispheric indices.

RESULTS: The median follow-up was 20 months. During this period, 8 patients experienced recurrent events, and 15 did not. The percentage signal change in GM in the MCA territory was significantly decreased in those patients with recurrent events compared with those without $(2.39 \pm 0.22$ versus $2.70 \pm 0.42, P=.032)$. The normal hemispheric index predicted event-free survival during follow-up (median, 20 months) for both the combined outcome (recurrent events and/or death, log-rank, $P=.034$ ) and recurrent retinal or ipsilateral ischemic events only (log-rank, $P=.012$ ).

CONCLUSIONS: The hemispheric asymmetry index derived from hypercapnia fMRI showed hemodynamic impairment in more than half of the studied patients with carotid occlusion, and those patients showed a higher risk of recurrent ischemic symptoms.

ABBREVIATIONS: $\mathrm{BET}=$ brain extraction tool; $\mathrm{BOLD}=$ blood oxygen level-dependent; $\mathrm{CAO}=$ carotid artery occlusion; $\mathrm{CVR}=$ cerebrovascular reserve; $\mathrm{EC}-\mathrm{IC}=$ extracranial-intracranial; $\mathrm{ETCO}_{2}=$ end-tidal carbon dioxide; $\mathrm{hAI}=$ hemispheric asymmetry index; $\mathrm{PSC}=$ percentage signal change

O the $40 \%$ of patients presenting with stroke or TIA related to carotid atherosclerotic disease, $10 \%-15 \%$ are found to have an occluded carotid artery. ${ }^{1}$ The rate of subsequent recurrent stroke in carotid artery occlusion (CAO) has been estimated between $2.4 \%$ and $7 \%$ per year. ${ }^{2-4}$ This risk persists in the face of platelet inhibitory drugs and anticoagulation. ${ }^{5}$ A key factor in

Received February 22, 2015; accepted after revision September 1.

From the Sheffield Vascular Institute (S.D.G.), Northern General Hospital, Sheffield, UK; Department of Vascular Surgery (S.D.G., N.A., S.T.R.M.), Queens Medical Centre, Nottingham, UK; Department of Stroke Medicine (S.M.), Nottingham City Hospital, Nottingham, UK; and Department of Radiological Sciences (S.D.G., N.A., D.P.A.), Sir Peter Mansfield Imaging Centre, University of Nottingham, Nottingham, UK.

This work was supported by Nottingham University Hospitals NHS Trust, Royal College of Surgeons of England.

Please address correspondence to S.D. Goode, MD, Sheffield Vascular Institute, Northern General Hospital, Sheffield S5 7AU, UK; e-mail: s.goode@sheffield.ac.uk; Dorothee P. Auer, MD, Radiological Sciences, University of Nottingham, Queens Medical Centre, Nottingham, NG7 2UH, UK; e-mail: dorothee.auer@nottingham.ac.uk

http://dx.doi.org/10.3174/ajnr.A4739 predicting recurrent ischemic episodes in $\mathrm{CAO}$ is the presence of hemodynamic impairment, whereby patients with an exhausted cerebrovascular reserve (CVR) and therefore impaired autoregulatory capacity are at higher risk of recurrent episodes of ischemia. In the subgroup of patients with symptomatic $\mathrm{CAO}$ and hemodynamic impairment, the risk of recurrent stroke may be as high as $12 \%$ per year. $^{6}$

Various imaging techniques enable the assessment of cerebral hemodynamic status in patients with carotid artery disease, including PET, SPECT, transcranial Doppler, and, more recently, advanced MR imaging techniques. ${ }^{7,8}$ These imaging modalities probe different pathophysiologic responses to falling cerebral perfusion pressure, but there is no consensus on their relative clinical relevance. Autoregulatory vasodilation is the primary compensation for a decrease in cerebral perfusion pressure, which can be assessed by increased cerebral blood volume or reduced cerebrovascular reserve to vasodilatory stimuli. When CBF no longer meets metabolic demand, the oxygen extraction frac- 
Table 1: Summary details of 8 patients with recurrent symptoms

\begin{tabular}{lccccccl}
$\begin{array}{c}\text { Patient } \\
\text { No. }\end{array}$ & $\begin{array}{c}\text { Age } \\
\text { (yr) }\end{array}$ & Sex & $\begin{array}{c}\text { Presenting } \\
\text { Symptom }\end{array}$ & $\begin{array}{c}\text { Contralateral } \\
\text { Stenosis }\end{array}$ & hAl & $\begin{array}{c}\text { Days to } \\
\text { Recurrent Event }\end{array}$ & \multicolumn{1}{c}{$\begin{array}{c}\text { Details of } \\
\text { Recurrent Events }\end{array}$} \\
\hline 1 & 52 & M & Stroke & $0-30$ & 19.6 & 2 & Arm weakness \\
2 & 72 & M & TIA & $80-99$ & 15.4 & 24 & Transient episode right arm/leg weakness \\
3 & 83 & F & TIA & $60-69$ & 10.1 & 676 & Stroke \\
4 & 51 & M & Stroke & $0-30$ & 10.8 & 94 & Recurrent episodes of weakness/collapse \\
5 & 54 & M & Stroke & $0-30$ & 12.2 & 154 & Multiple episodes of collapse and loss of consciousness \\
6 & 53 & M & TIA & $0-30$ & 28.1 & 35 & Recurrent left hand and face numbness/weakness \\
7 & 84 & M & TIA & $50-59$ & 8.4 & 169 & Recurrent weakness \\
8 & 70 & M & TIA & $0-30$ & 11.6 & 715 & Leg weakness \\
\hline
\end{tabular}

tion increases, which is considered index misery perfusion or stage II hemodynamic impairment versus stage I when the oxygen extraction fraction is intact. ${ }^{1}$ The concept of sequential progression of hemodynamic impairment was later challenged, ${ }^{9}$ and CVR was found more sensitive to hemodynamic white matter ischemia than the oxygen extraction fraction. ${ }^{10}$ In fact, both CVR and oxygen extraction fraction abnormalities were found to predict future strokes. ${ }^{5,11,12}$ While PET is considered the most reliable technique to assess hemodynamic impairment, controversies remain regarding the best quantification method and threshold, ${ }^{13}$ and the high cost may be prohibitive as a screening tool. ${ }^{14}$

A reliable MR imaging-based assessment of hemodynamic impairment would be desirable because it combines the advantage of noninvasiveness with spatial mapping and no radiation, has minimal operator-dependence, and could be integrated into the routine MR imaging work-up of patients with stroke/TIA. Hypercapnia blood oxygen level-dependent (BOLD) fMRI allows the assessment of CVR with high test-retest reproducibility. ${ }^{15}$ Normalized CVR metrics derived from hypercapnia BOLD fMRI were found to be sufficiently sensitive to detect hemodynamic impairment in patients with carotid artery disease and to demonstrate CVR improvement after carotid endarterectomy. ${ }^{8,15}$ We do, however, lack validation studies that investigate whether and how much hypercapnia BOLD-based CVR impairment predicts recurrent events.

To address this knowledge gap, we investigated whether a predefined threshold of hemispheric asymmetry in CVR predicts recurrent symptoms in patients with CAO who had previously experienced ipsilateral symptoms during the past 12 months. The threshold of CVR impairment was derived with hemispheric asymmetry from a previous study in healthy volunteers. ${ }^{15}$ We focused on patients with CAO for 2 reasons: First, in carotid occlusion, there is no ipsilateral flow in the carotid artery; therefore, potential confounding issues of embolization from proximal carotid plaque or the cardiac source can be excluded. Second, in patients with CAO for whom the efficacy of recanalization therapies lacks evidence, there is a particular need to establish validated markers of clinically relevant hemodynamic impairment.

\section{MATERIALS AND METHODS \\ Recruitment}

Patients with transient ischemic attacks or stroke were prospectively and consecutively identified for 2.5 years at the vascular clinics of a tertiary referral acute hospital trust (Nottingham University Hospital NHS Trust). Eligibility criteria included CAO on duplex scanning. All patients had experienced stroke, TIAs, or amaurosis fugax in the past 12 months. Participants gave written informed consent, and the study was approved by the hospital research and development department and the local research ethics committee (Queens Medical Centre, Nottingham).

We studied 23 patients with a mean age of $67.5 \pm 9$ years; there were 21 men and 2 women. The contralateral ICA was stenosed in 9 patients: $50 \%-59 \%(n=1), 60 \%-69 \%(n=2), 70 \%-79 \%$ $(n=1), 80 \%-95 \%(n=4)$, and $100 \%(n=1)$. Patients were assessed for recurrent ischemic events from 30 days before MR imaging to loss to follow-up, study end, or death. We chose this follow-up to avoid confounds from delays between the initial clinic visit and MR imaging scheduling, to ensure that we identified recurrent symptoms following the initial clinical events leading to presentation to the TIA/stroke clinic, but before MR imaging.

Fifteen patients had only a single symptomatic event, and the remaining 8 patients had recurrent symptomatic events following their initial episode (Table 1). By study end, 3 patients had died, all from noncerebrovascular causes. Five patients underwent contralateral carotid endarterectomy and were not followed-up beyond this time point because CVR is altered following surgical revascularization. ${ }^{8}$

\section{Hemodynamic Assessment}

All subjects were asked not to consume alcohol or caffeine for 4 hours before the scanning session. MR imaging studies were performed on a clinical 1.5T scanner (Intera; Philip Healthcare, Best, Netherlands). A standard 8-channel head coil was used for imaging, with a standard gradient-echo echo-planar sequence (TR/TE, 3500/60 ms; flip angle, $90^{\circ}$; matrix size, $64 \times 64$; FOV, $192 \mathrm{~mm}$; with 33 sections, $3 \mathrm{~mm}$ thick and no gap). A total of 160 volumes (approximately 9-minute acquisition time) were acquired for each experiment. End-tidal carbon dioxide $\left(\mathrm{ETCO}_{2}\right)$ was controlled by using a standard nonrebreathing anesthetic circuit by using two 1-way valves to prevent rebreathing. $\mathrm{ETCO}_{2}$ was continuously monitored via a sampling tube at the mouthpiece level, with recordings being made during the whole experiment. Two periods of hypercapnia lasting 9 minutes were intercalated with 3 periods of normocapnia. We administered $10 \% \mathrm{CO}_{2}$, aiming for an increase in $\mathrm{ETCO}_{2}$ between 7 and $8 \mathrm{~mm} \mathrm{Hg}$ for near-maximum cerebral vasodilation. Control of $\mathrm{CO}_{2}$ gas flow was via an external source outside the MR imaging scanner. We continuously monitored the subject's blood pressure, pulse, and arterial oxygen saturation by using an MR imaging-compatible device (Invivo; Siemens, Erlangen, Germany).

AJNR Am J Neuroradiol 37:904-09 May 2016 www.ajnr.org 905 


\section{Data Analysis}

All data were analyzed by using the FMRIB Software Library (FSL; http://www.fmrib.ox.ac.uk/fsl) and the FMRIB Expert Analysis Tool (FEAT; http://fsl.fmrib.ox.ac.uk/fsl/feeds/data/fmri.feat/ report_prestats.html) using standard preprocessing with highpass filtering, smoothing, and motion correction by using an intramodal motion-correction tool (MCFLIRT; http://fsl.fmrib.ox. ac.uk/fsl/fslwiki/MCFLIRT) as previously described. ${ }^{8,15}$ In brief, $\mathrm{ETCO}_{2}$ data acquired during the scanning session were incorporated into the design matrix during the analysis. The FSL Brain Extraction Tool (BET; http://fsl.fmrib.ox.ac.uk/fsl/fslwiki/BET) was used to remove nonbrain structures from the anatomic T1-weighted scans. Following this step, the T1 images were segmented into gray and white matter by using the FMRIB Automated Segmentation Tool (FAST; http://fsl.fmrib.ox.ac.uk/fsl/fslwiki/).

BOLD signal changes were derived from individualized gray matter MCA territory masks by using the FSL FEAT query, following conversion from standard space into functional space. We used $\mathrm{ETCO}_{2}$ as a regressor of no interest; thus, corrected BOLD responses were expressed as percentage signal change (PSC). To achieve higher robustness against technical and interindividual physiologic factors, we then normalized data to the contralateral hemisphere and expressed them as hemispheric asymmetry. The hemispheric asymmetry index (hAI) was determined according to hAI $=200 \times($ PSC Asymptomatic Hemisphere - PSC Symptomatic Hemisphere) / (PSC Sum of Both Hemispheres) as reported. ${ }^{16}$ The threshold to define abnormal CVR as the index of hemodynamic impairment was derived from the $95 \%$ confidence interval boundary from a group of previously studied healthy volunteers. We derived a level of $\mathrm{hAI}>8$ as an impaired CVR, reflecting a 7.7\% lower ipsilateral-thancontralateral BOLD response $\mathrm{CO}_{2}$ challenge. ${ }^{15}$

\section{Statistical Analysis}

Statistical calculations were performed by using the Statistical Package for the Social Sciences (SPSS, Version 16.0; IBM, Armonk, New York) software. Statistical significance was set as $P<.05 . T$ tests and $U$ tests were performed for parametric and nonparametric variables, respectively. The effect of hemodynamic impairment on the rate of recurrent cerebral ischemic events was examined by using Kaplan-Meier survival analysis with the log-rank test.

\section{Group Analysis to Locate CVR Differences between Patients with CAO and Single versus Recurrent Events}

To further investigate regional variation in CVR, we performed a second group-level analysis by using FMRIB Local Analysis of Mixed Effects (FLAME) ${ }^{17,18}$ to derive group-averaged maps of the hypercapnia BOLD response separately for patients presenting with single versus those with recurrent symptoms. An additional step in the preprocessing was necessary for this analysis method, whereby the raw data from the patients with left hemispheric symptoms were flipped so that all images were "symptomatic" in the right hemisphere. Higher level group analysis was performed by using mixed-effect analysis (FLAME) with activation levels set at $P<.05$, uncorrected.

\section{RESULTS}

Median follow-up was 20 months. During this period, 8 patients experienced recurrent events, and 15 did not. There was no sig-
Table 2: Patient demographics according to new events or no

\begin{tabular}{|c|c|c|c|}
\hline & No Events & New Events & $P$ Value \\
\hline Age (yr) & 68 & 66 & .64 \\
\hline \multicolumn{4}{|l|}{ Sex $(\%)$} \\
\hline Male & 46 & 42 & .63 \\
\hline Female & 8 & 4 & \\
\hline Ipsilateral GM PSC (mean) & $2.70 \pm 0.41$ & $2.40 \pm 0.22$ & .03 \\
\hline Contralateral GM PSC (mean) & $2.77 \pm 0.49$ & $2.74 \pm 0.40$ & .91 \\
\hline hAl (mean) & $3.98 \pm 5.73$ & $13.01 \pm 7.58$ & .004 \\
\hline $\mathrm{ETCO}_{2}$ change (mean) & $7.0 \pm 1.8$ & $8.0 \pm 3.3$ & .34 \\
\hline MAP (mean) & $114.5 \pm 12.4$ & $104 \pm 16.8$ & .11 \\
\hline \multicolumn{4}{|l|}{ Contralateral carotid disease } \\
\hline $0 \%-30 \%$ & $9(60 \%)$ & $5(62.5 \%)$ & \\
\hline $50 \%-70 \%$ & $1(6.7 \%)$ & $2(25 \%)$ & .651 \\
\hline $70 \%-79 \%$ & $1(6.7 \%)$ & 0 & \\
\hline $80 \%-99 \%$ & $3(20 \%)$ & $1(12.5 \%)$ & \\
\hline $100 \%$ & $1(6.7 \%)$ & 0 & \\
\hline Hypertension (\%) & 100 & 100 & 1 \\
\hline Ischemic heart disease & $3(21.4 \%)$ & $1(11 \%)$ & .52 \\
\hline Diabetes & $3(21 \%)$ & $4(44 \%)$ & .24 \\
\hline \multicolumn{4}{|l|}{ Smoking } \\
\hline Nonsmoker & 0 & $1(12.5 \%)$ & \\
\hline Ex-smoker & $7(50 \%)$ & $3(37.5 \%)$ & .37 \\
\hline Smoker & $7(50 \%)$ & $4(50 \%)$ & \\
\hline \multicolumn{4}{|l|}{ Type of presenting symptoms } \\
\hline Amaurosis fugax & $4(27 \%)$ & 0 & \\
\hline Stroke & $8(53 \%)$ & $4(50 \%)$ & .158 \\
\hline TIA & $3(20 \%)$ & $4(50 \%)$ & \\
\hline
\end{tabular}

Note:-MAP indicates mean arterial pressure.

nificant difference in patient demographics between patients with single and recurrent events (Table 2). Twelve patients had an abnormal CVR defined as $\mathrm{hAI} \geq 8$. Table 1 presents the details of patients who had recurrent events.

\section{CVR Comparison between Patients with Single and Recurrent Events}

Normalized ipsilateral territorial PSC (GM MCA) was significantly decreased in those patients with recurrent events compared with those with single events $(2.39 \pm 0.22$ versus $2.70 \pm 0.42, P=$ .032). However, in the contralateral MCA territory, there was no difference in PSC $(2.74 \pm 0.4$ versus $2.77 \pm 0.5, P=.91)$. Mean hAI was significantly larger, reflecting significantly more lateralization to the contralateral hemisphere in patients with recurrent events (13 \pm 7.5 versus $4 \pm 5.7$; $t$ test, $P=.004$ ) than for those patients with only single events. Seven of the 8 patients who experienced recurrent events during the follow-up had abnormal hemodynamic status (hAI $\geq 8$ ) compared with only $5 / 15$ of those with single events.

\section{Survival Analysis}

Kaplan-Meier analysis was performed for patients with no CVR impairment (hAI $<8$ ) versus those with CVR impairment (hAI $\geq 8$ ). Normal CVR significantly predicted event-free survival during follow-up (median, 20 months) for both the combined outcome (recurrent events and/or death; log-rank, $P=.034$, Fig 1) and recurrent retinal or ipsilateral ischemic events only (log-rank, $P=.012)$.

\section{CVR Group Maps}

Group-averaged maps illustrate only mild asymmetry in CVR expressed as hypercapnia-induced BOLD signal increase in patients 
with single events (Fig 2B). There was also no apparent regional variation of CVR in patients with single episodes. In contrast, patients with recurrent symptoms showed an almost complete loss of CVR in the affected hemisphere (displayed on the right regardless of original side due to flipping of the brain during data analysis) distal to the $\mathrm{CAO}$; in particular, there were no differences between territorial and watershed areas.

\section{DISCUSSION}

Using noninvasive hypercapnia BOLD fMRI to assess CVR, we found a high rate of hemodynamic impairment in patients with symptomatic carotid artery occlusion. Most important, CVR reduction was more pronounced in patients with recurrent versus sin-

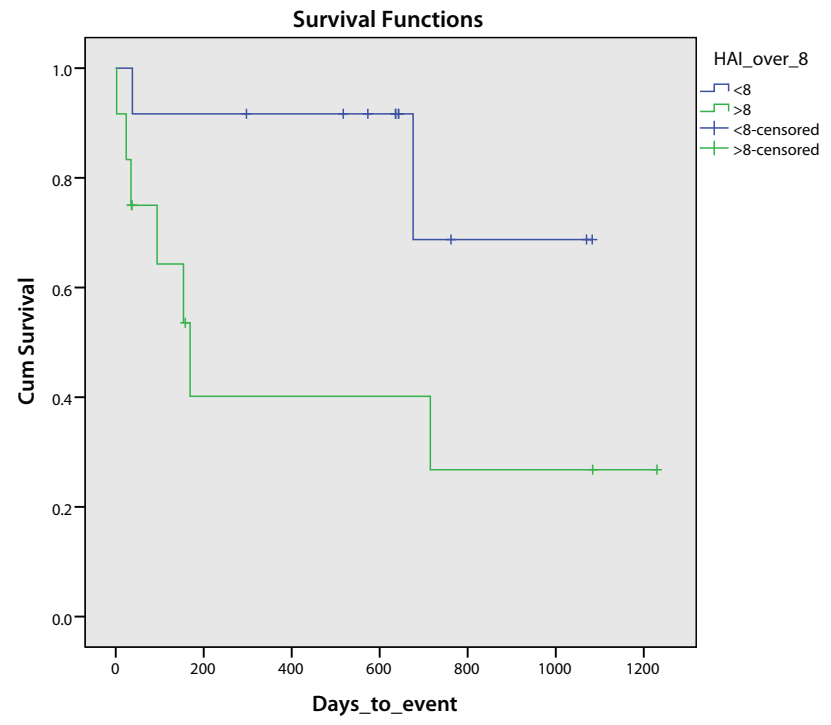

FIG 1. Kaplan-Meier graph showing recurrent ischemic events and death following the initial CVR scan (log-rank $=0.034$ ).

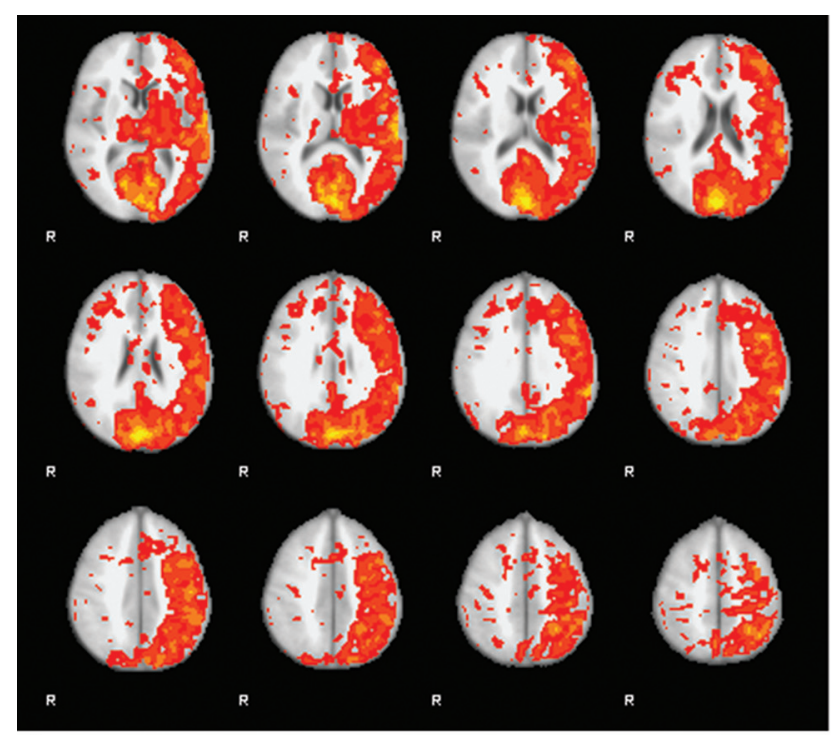

A gle ischemic events, and the presence of hemodynamic impairment significantly shortened event-free survival during the follow-up.

More than half (12/23) of the patients with symptomatic CAO recruited for this study had hemispheric asymmetry indices outside the previously determined 95\% CI from healthy volunteers. We chose this cutoff to define CVR reduction to reliably include patients with early (stage 1) hemodynamic impairment, while limiting inclusion of those within the upper distribution of physiologic variability. As seen for other modalities, this quantification of hemodynamic impairment can be achieved on the basis of hemispheric indices because confidence intervals are much wider for ipsilateral quantitative BOLD responsiveness, even after controlling for $\mathrm{ETCO}_{2}$. We were able to complete hypercapnia fMRI in our patient cohort without complications, and the methodology was well-tolerated. For selected patients who might not tolerate the breathing mask setup well, the proposed CVR method could be easily adapted to a similar hemispheric asymmetry threshold test by using acetazolamide.

Patients with recurrent events showed ipsilateral reduced CVR and resulting increased hAI compared with those with single events. Moreover, $\mathrm{hAI} \geq 8$ allowed prediction of the risk of recurrent events. This finding adds to those in previous studies that investigated associations between impaired CVR and increased stroke risk. ${ }^{4,11,19-30}$ Nine of 12 studies found a positive association of reduced or exhausted CVR and recurrent risk of future ischemic events or stroke by using a range of vasodilatory stimuli and CVR metrics. The negative findings may be explained by insufficient vasodilatory stimuli because 2 of the studies with negative findings ${ }^{3,4}$ used carbogen (typically $5 \% \mathrm{CO}_{2}$ ), whereas Markus and Cullinane ${ }^{11}$ showed that exhausted CVR as assessed by hypercapnia transcranial Doppler with $6 \%$ or $8 \% \mathrm{CO}_{2}$ independently predicted future stroke and that the prediction was stronger for $8 \% \mathrm{CO}_{2}$ challenges.

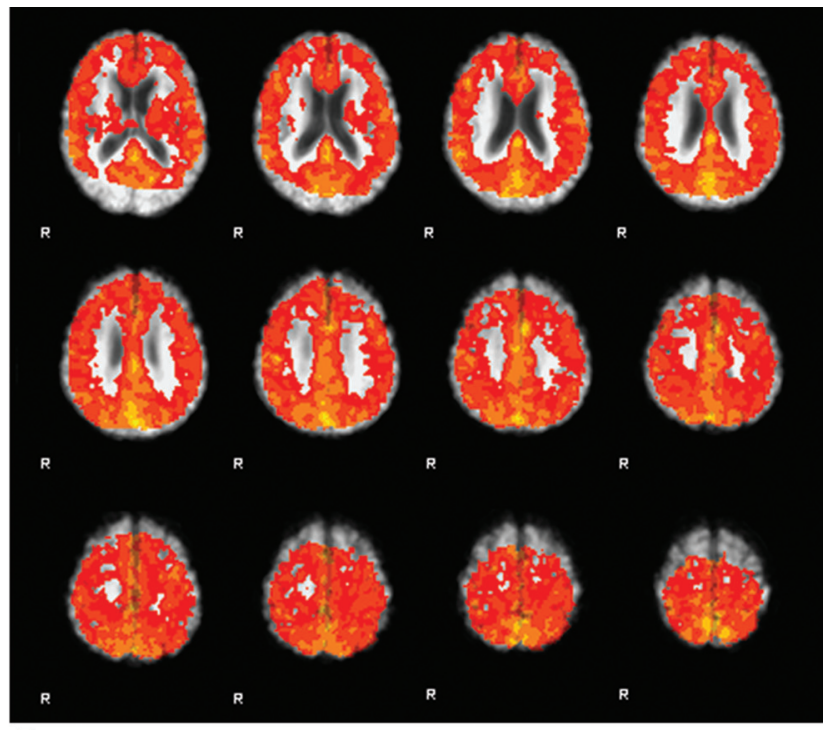

B

FIG 2. Hypercapnia BOLD response maps (threshold) in patients with symptomatic CAO. Color code for BOLD PSC shows that the higher the BOLD PSC the higher the CVR. Note that the symptomatic hemisphere is displayed on the left (right by radiologic convention). $A$, Patients who developed recurrent events during follow-up. B. Those who did not develop recurrent events during follow-up. Groupaveraged CVR maps show mild asymmetry in CVR expressed as hypercapnia-induced BOLD signal changes in patients with recurrent events $(A)$ and single events $(B)$. 
Our study was not powered to investigate the risk of future stroke, but any recurrent ischemic event was noted in $87 \%$ of patients with CAO and CVR impairment compared with $10 \%$ in those with intact CVR. This finding compares well with those in recent larger studies showing about 6-fold higher risk of recurrent events in patients with hemodynamic impairment: The stroke rate per year in patients with symptomatic CAO with medical management alone was about $18 \%$ compared with about a $3 \%$ yearly risk in patients with normal hemodynamics. ${ }^{31,32}$ Prevention of subsequent stroke in patients with CAO remains a difficult challenge; revascularization techniques can be used to improve cerebral perfusion in an attempt to prevent ischemia, such as the extracranialintracranial (EC-IC) bypass surgery or endovascular techniques. ${ }^{33}$ EC-IC bypass has also been shown to improve the CVR of patients following intervention, ${ }^{34}$ and Mandell et al, ${ }^{35}$ by using $\mathrm{CO}_{2}$ BOLD fMRI, showed that preoperative CVR measurements could predict the hemodynamic effects of EC-IC bypass surgery.

However, bypass surgery has been largely abandoned since the publication of a large negative randomized controlled trial in 1985, which showed no benefit to patients with CAO from a bypass operation. ${ }^{36}$ This study received widespread criticism related to its design and implementation. During the past few years, 2 randomized controlled trials were set up to reassess the benefit of EC-IC bypass surgery in patients with hemodynamic compromise: the Japanese EC-IC Bypass Trial (JET) and the Carotid Occlusion Surgery Study (COSS), ${ }^{37,38}$ with differing results. In these studies, patients with hemodynamically significant carotid occlusions were randomized to best medical therapy or to an operation and best medical therapy. The methods of hemodynamic assessment in these studies are SPECT for the JET study and PET for the COSS study. The second interim analysis from the JET study showed a significant benefit at 2 years for patients undergoing an EC-IC bypass surgery. ${ }^{37}$

However, more recently, the COSS study ${ }^{32}$ was stopped due to an interim futility analysis suggesting that EC-IC bypass surgery plus medical therapy compared with medical therapy alone did not reduce the risk of recurrent ipsilateral ischemic stroke at 2 years. A core aspect of this study was the physiologic selection of patients with signs of hemodynamic impairment by using PET, but the chosen semi-quantitative oxygen extraction fraction has been criticized because it lacks validation to predict recurrent events. ${ }^{13}$ More recently, the Randomized Evaluation of Carotid Occlusion and Neurocognition study published its results showing no improvement in cognition for patients undergoing EC-IC bypass for symptomatic carotid occlusion with an increased oxygen extraction fraction. ${ }^{39}$

In the future, it is likely that EC-IC bypass may be superseded by newer endovascular techniques for which there have been recent feasibility studies showing promising results by using a minimally invasive recanalization technique with proximal cerebral protection and stent placement for symptomatic acute and chronic carotid artery occlusion. ${ }^{33}$

One of the main problems of using nuclear medicine-based techniques such as PET and SPECT to assess hemodynamic impairment is the relatively large dose of ionizing radiation to the patient in addition to cost and access. A method for assessment of cerebral hemo- dynamics without radiation risks is obviously preferable. Hypercapnia fMRI offers a potential alternative in this patient group without the use of radiation. Previous work shows the accuracy and reproducibility of our technique to assess CVR or stage I hemodynamic impairment ${ }^{15}$ and also the changes in CVR following carotid endarterectomy. ${ }^{8}$ Therefore, the ability to perform a quick and easy assessment of the hemodynamic status without the risk of ionizing radiation is particularly useful for the future of mainstream medical imaging.

We performed a group analysis of CVR maps to compare the pattern of hemodynamic impairment in patients with single versus recurrent events. There was a marked difference with almost complete loss of CVR capacity within the core MCA territory in addition to grossly altered watershed areas. This result highlighted the tissue at high risk for ischemic compromise with maximal dilation of the cerebral vessels and therefore no further dilating capacity to compensate for future cerebral autoregulatory demands. These maps provide us with a visual representation of anatomic CVR and thus allow us to assess individual areas at risk of hemodynamic impairment and could be further used to test the validity of CVR to predict hemodynamic tissue at risk. It will be of interest to further compare the location of CVR exhaustion with the location of future hemodynamic infarctions.

Our study is clearly limited by the small number of patients and the variable length of follow-up. We have only clinical follow-up on our patients, and we did not have any recurrent imaging. Further evaluation of patients' CVR with recurrent events is needed as a prospective study. A further limitation of this study is the lack of any reference imaging standard used for comparison; further studies are needed to evaluate and directly compare hypercapnia fMRI with the accepted imaging methods of CVR, such as PET or SPECT. There was heterogeneity in the patients' contralateral carotid disease within the study; however, we have found, from previous unpublished work, that different and increasing degrees of carotid disease do not necessarily correlate with increasing degrees of hemodynamic impairment.

\section{CONCLUSIONS}

In this small study, we have shown that the hemispheric asymmetry index derived from hypercapnia BOLD fMRI demonstrated hemodynamic impairment in more than half of our patient cohort with carotid occlusion, and we found that those patients had an elevated risk of recurrent ischemic symptoms. This noninvasive technique may thus be helpful in selecting patients for recanalization with bypass treatment or endovascular revascularization.

Disclosures: Stephen D. Goode—RELATED: Grant: Royal College of Surgeons. * Dorothee P. Auer-RELATED: Grant: Special Trustee, Nottingham University Hospital Trust.* *Money paid to the institution.

\section{REFERENCES}

1. Powers WJ. Cerebral hemodynamics in ischemic cerebrovascular disease. Ann Neurol 1991;29:231-40 CrossRef Medline

2. Hankey GJ, Warlow CP. Prognosis of symptomatic carotid artery occlusion: an overview. Cerebrovasc Dis 1991;1:245-56 CrossRef

3. Klijn CJ, Kappelle LJ, van Huffelen AC, et al. Recurrent ischemia in symptomatic carotid occlusion: prognostic value of hemodynamic factors. Neurology 2000;55:1806-12 CrossRef Medline

4. Persoon S, Luitse MJ, de Borst GJ, et al. Symptomatic internal ca- 
rotid artery occlusion: a long-term follow-up study. J Neurol Neurosurg Psychiatry 2011;82:521-26 CrossRef Medline

5. Grubb RL Jr, Derdeyn CP, Fritsch SM, et al. Importance of hemodynamic factors in the prognosis of symptomatic carotid occlusion. JAMA 1998;280:1055-60 CrossRef Medline

6. Klijn CJ, Kappelle LJ, Algra A, et al. Outcome in patients with symptomatic occlusion of the internal carotid artery or intracranial arterial lesions: a meta-analysis of the role of baseline characteristics and type of antithrombotic treatment. Cerebrovasc Dis 2001;12: 228-34 CrossRef Medline

7. Bokkers RP, van Osch MJ, van der Worp HB, et al. Symptomatic carotid artery stenosis: impairment of cerebral autoregulation measured at the brain tissue level with arterial spin-labeling MR imaging. Radiology 2010;256:201-08 CrossRef Medline

8. Goode SD, Altaf N, Auer DP, et al. Carotid endarterectomy improves cerebrovascular reserve capacity preferentially in patients with preoperative impairment as indicated by asymmetric BOLD response to hypercapnia. Eur J Vasc Endovasc Surg 2009;38:546-51 CrossRef Medline

9. Derdeyn CP, Videen TO, Yundt KD, et al. Variability of cerebral blood volume and oxygen extraction: stages of cerebral haemodynamic impairment revisited. Brain 2002;125:595-607 CrossRef Medline

10. Nemoto EM, Yonas H, Kuwabara H, et al. Identification of hemodynamic compromise by cerebrovascular reserve and oxygen extraction fraction in occlusive vascular disease. J Cereb Blood Flow Metab 2004;24:1081-89 Medline

11. Markus H, Cullinane M. Severely impaired cerebrovascular reactivity predicts stroke and TIA risk in patients with carotid artery stenosis and occlusion. Brain 2001;124:457-67 CrossRef Medline

12. Yamauchi H, Fukuyama H, Nagahama Y, et al. Significance of increased oxygen extraction fraction in five-year prognosis of major cerebral arterial occlusive diseases. J Nucl Med 1999;40:1992-98 Medline

13. Carlson AP, Yonas H, Chang YF, et al. Failure of cerebral hemodynamic selection in general or of specific positron emission tomography methodology?: Carotid Occlusion Surgery Study (COSS). Stroke 2011;42:3637-39 CrossRef Medline

14. Garrett MC, Komotar RJ, Starke RM, et al. Radiographic and clinical predictors of hemodynamic insufficiency in patients with atheroocclusive disease. J Stroke Cerebrovasc Dis 2008;17:340-43 CrossRef Medline

15. Goode SD, Krishan S, Alexakis C, et al. Precision of cerebrovascular reactivity assessment with use of different quantification methods for hypercapnia functional MR imaging. AJNR Am J Neuroradiol 2009;30:972-77 CrossRef Medline

16. de Boorder MJ, van der Grond J, van Dongen AJ, et al. SPECT measurements of regional cerebral perfusion and carbon dioxide reactivity: correlation with cerebral collaterals in internal carotid artery occlusive disease. J Neurol 2006;253:1285-91 CrossRef Medline

17. Beckmann CF, Jenkinson M, Smith SM. General multilevel linear modeling for group analysis in FMRI. Neuroimage 2003;20:1052-63 CrossRef Medline

18. Woolrich MW, Behrens TE, Beckmann CF, et al. Multilevel linear modelling for FMRI group analysis using Bayesian inference. $\mathrm{Neu}$ roimage 2004;21:1732-47 CrossRef Medline

19. Kleiser BW, Widder B. Course of carotid artery occlusions with impaired cerebrovascular reactivity. Stroke 1992;23:171-74 CrossRef Medline

20. Yonas H, Smith HA, Durham SR, et al. Increased stroke risk predicted by compromised cerebral blood flow reactivity. J Neurosurg 1993;79:483-89 CrossRef Medline

21. Widder B, Kleiser B, Krapf H. Course of cerebrovascular reactivity in patients with carotid artery occlusions. Stroke 1994;25:1963-67 CrossRef Medline
22. Webster MW, Makaroun MS, Steed DL, et al. Compromised cerebral blood flow reactivity is a predictor of stroke in patients with symptomatic carotid artery occlusive disease. J Vasc Surg 1995;21:33844; discussion 344-45 Medline

23. Powers WJ, Tempel LW, Grubb RL Jr. Influence of cerebral hemodynamics on stroke risk: one-year follow-up of 30 medically treated patients. Ann Neurol 1989;25:325-30 CrossRef Medline

24. Hasegawa Y, Yamaguchi T, Tsuchiya T, et al. Sequential change of hemodynamic reserve in patients with major cerebral artery occlusion or severe stenosis. Neuroradiology 1992;34:15-21 CrossRef Medline

25. Yokota C, Hasegawa Y, Minematsu K, et al. Effect of acetazolamide reactivity on [corrected] long-term outcome in patients with major cerebral artery occlusive diseases. Stroke 1998;29:640-44 CrossRef Medline

26. Ogasawara K, Ogawa A, Yoshimoto T. Cerebrovascular reactivity to acetazolamide and outcome in patients with symptomatic internal carotid or middle cerebral artery occlusion: a xenon-133 singlephoton emission computed tomography study. Stroke 2002;33: 1857-62 CrossRef Medline

27. Vernieri FP, Pasqualetti P, Passarelli F, et al. Outcome of carotid artery occlusion is predicted by cerebrovascular reactivity. Stroke 1999;30:593-98 CrossRef Medline

28. Kuroda S, Houkin K, Kamiyama H, et al. Long-term prognosis of medically treated patients with internal carotid or middle cerebral artery occlusion: can acetazolamide test predict it? Stroke 2001;32: 2110-16 CrossRef Medline

29. Isozaki M, Arai $\mathrm{Y}$, Kudo $\mathrm{T}$, et al. Clinical implication and prognosis of normal baseline cerebral blood flow with impaired vascular reserve in patients with major cerebral artery occlusive disease. Ann Nucl Med 2010;24:371-77 CrossRef Medline

30. Kimiagar I, Bass A, Rabey JM, et al. Long-term follow-up of patients with asymptomatic occlusion of the internal carotid artery with good and impaired cerebral vasomotor reactivity. Eur J Neurol 2010; 17:1285-90 CrossRef Medline

31. Jeffree RL, Stoodley MA. STA-MCA bypass for symptomatic carotid occlusion and haemodynamic impairment. J Clin Neurosci 2009;16: 226-35 CrossRef Medline

32. Powers WJ, Clarke WR, Grubb RL Jr, et al; COSS Investigators. Extracranial-intracranial bypass surgery for stroke prevention in hemodynamic cerebral ischemia: the Carotid Occlusion Surgery Study randomized trial. JAMA 2011;306:1983-92 CrossRef Medline

33. Shojima M, Nemoto S, Morita A, et al. Protected endovascular revascularization of subacute and chronic total occlusion of the internal carotid artery. AJNR Am J Neuroradiol 2010;31:481-86 CrossRef Medline

34. Gibbs JM, Wise RJ, Thomas DJ, et al. Cerebral haemodynamicchanges after extracranial-intracranial bypass-surgery. $J$ Neurol Neurosurg Psychiatry 1987;50:140-50 CrossRef Medline

35. Mandell DM, Han JS, Poublanc J, et al. Quantitative measurement of cerebrovascular reactivity by blood oxygen level-dependent MR imaging in patients with intracranial stenosis: preoperative cerebrovascular reactivity predicts the effect of extracranial-intracranial bypass surgery. AJNR Am J Neuroradiol 2011;32:721-27 CrossRef Medline

36. EC/IC Bypass Study Group. Failure of extracranial-intracranial arterial bypass to reduce the risk of ischemic stroke: results of an international randomized trial. $N$ Engl J Med 1985;313:1191-200 CrossRef Medline

37. JET Study Group. Japanese EC-IC Bypass Trial (JET Study): the second interim analysis. Surg Cereb Stroke 2002;30:434-37 CrossRef

38. Grubb RL Jr, Powers WJ, Derdeyn CP, et al. The Carotid Occlusion Surgery Study. Neurosurg Focus 2003;14:e9 Medline

39. Marshall RS, Festa JR, Cheung YK, et al; RECON Investigators. Randomized Evaluation of Carotid Occlusion and Neurocognition (RECON) trial: main results. Neurology 2014;82:744-51 CrossRef Medline 